\title{
Response of Southern Ocean Ventilation to Changes in Midlatitude Westerly Winds
}

\author{
DARRYN W. WAUGH \\ Department of Earth and Planetary Sciences, The Johns Hopkins University, Baltimore, Maryland, and School of \\ Mathematics and Statistics, University of New South Wales, Sydney, New South Wales, Australia \\ ANDREW MCC. HOGG \\ Research School of Earth Sciences, and Australian Research Council Centre of Excellence for Climate Extremes, \\ Australian National University, Canberra, Australian Capital Territory, Australia \\ PAul SPenCE AND MATTHEW H. ENGLAND \\ Climate Change Research Centre, and Australian Research Council Centre of Excellence for Climate Extremes, \\ University of New South Wales, Sydney, New South Wales, Australia \\ THOMAS W. N. HAINE \\ Department of Earth and Planetary Sciences, The Johns Hopkins University, Baltimore, Maryland
}

(Manuscript received 14 January 2019, in final form 11 May 2019)

\begin{abstract}
Changes in ventilation of the Southern Hemisphere oceans in response to changes in midlatitude westerly winds are examined by analyzing the ideal age tracer from global eddy-permitting ocean-ice model simulations in which there is an abrupt increase and/or a meridional shift in the winds. The age response in mode and intermediate waters is found to be close to linear; the response of a combined increase and shift of peak winds is similar to the sum of the individual responses to an increase and a shift. Further, a barotropic response, following Sverdrup balance, can explain much of the age response to the changes in wind stress. There are similar peak decreases (of around 50 years) in the ideal age for a $40 \%$ increase or $2.5^{\circ}$ poleward shift in the wind stress. However, while the age decreases throughout the thermocline for an increase in the winds, for a poleward shift in the winds the age increases in the north part of the thermocline and there are decreases in age only south of $35^{\circ} \mathrm{S}$. As a consequence, the change in the volume of young water differs, with a $15 \%$ increase in the volume of water with ages younger than 50 years for a $40 \%$ increase in the winds but essentially no change in this volume for a $2.5^{\circ}$ shift. As ventilation plays a critical role in the uptake of carbon and heat, these results suggest that the storage of anthropogenic carbon and heat in mode and intermediate waters will likely increase with a strengthening of the winds, but will be much less sensitive to a meridional shift in the peak wind stress.
\end{abstract}

\section{Introduction}

The transport of surface waters into the interior (ventilation) of the southern oceans plays a critical role in the uptake of heat, carbon, and nutrients (e.g., Gille 2008; Sabine et al. 2004; Sarmiento et al. 2004). This ventilation is, at least partially, controlled by the westerly winds over the southern mid- and high latitudes, and these winds have intensified and shifted poleward over

Corresponding author: Darryn Waugh, waugh@jhu.edu the last few decades in austral summer (DecemberFebruary), due to the combined effects of stratospheric ozone depletion and increases in greenhouse gases (e.g., Thompson et al. 2011; Swart and Fyfe 2012). There is observational evidence for an accompanying decrease in ventilation time scale in the thermocline (e.g., Waugh et al. 2013; Ting and Holzer 2017) as well as changes in heat content (e.g., Cai et al. 2010; Roemmich et al. 2015; Armour et al. 2016), carbon uptake (e.g., Le Quéré et al. 2007) and mode water properties (Gao et al. 2018). However, it is difficult to attribute these decreases in 
ventilation time to wind stress changes because of a lack of a quantitative understanding of the change in ventilation for an increase or shift in the winds. This attribution is also needed to understand how the ventilation may change in the future, as the strength and latitude of the peak westerly winds are expected to continue to change, although likely at a different rate than in the past because the effects of stratospheric ozone recovery will oppose that from the continued increase in greenhouse gases (e.g., Son et al. 2008; Bracegirdle et al. 2013).

One measure of the ventilation time of the thermocline is the ideal age; the mean time since water was in the surface layer. Several modeling studies have examined the change in ideal age in response to either idealized perturbations to the southern wind stress (Farneti and Gent 2011; Waugh 2014) or climate change scenarios (e.g., Bryan et al. 2006; Gnanadesikan et al. 2007), and have shown that there is a decrease in the ideal age of thermocline waters when there is an increase and poleward shift of the southern winds. However, these studies did not quantify the age-wind stress relationships (i.e., they did not quantify the decrease in age for a given increase in wind stress, or the relative importance of an increase versus meridional shift in the peak winds). Also, the mechanisms involved in the change in age were not examined in detail. Furthermore, these studies almost exclusively used coarse-resolution climate models that rely on eddy parameterizations, and there is uncertainty in how realistic such models are in reproducing any changes in stirring and transport.

Here we address these issues by examining the change in ideal age in a suite of global eddy-permitting oceansea ice model simulations that include separate abrupt intensification or poleward shift wind stress perturbations, as well as a simulation with a combined increase and shift. Several previous studies have used these simulations to examine the impact of changes in winds of the ocean flow (Spence et al. 2014; Hogg et al. 2017; Downes et al. 2017). Hogg et al. (2017) examined changes in the meridional overturning circulation (MOC) and energetics, and showed that an increase in the winds enhances the upper cell of the MOC whereas a poleward shift in the winds leads to a weaker upper cell. Downes et al. (2017) examined changes in Subantarctic Mode Water (SAMW) and Antarctic Intermediate Water (AAIW) subduction rates, and showed that the integrated SAMW and AAIW subduction rates respond differently to the wind perturbations: The poleward shift in winds has a larger impact on SAMW subduction than intensification of the winds, whereas there is a similar, weaker response of AAIW subduction to increase or shift in the winds. We extend on these previous studies by examining the change in the ideal age and ocean ventilation in response to these idealized wind-forcing perturbations.

As the largest uptake of anthropogenic carbon and heat is observed in southern mode and intermediate waters (e.g., Sabine et al. 2004; Cai et al. 2010) we will focus here on the characteristics of the ideal age in these waters. From the four simulations we can quantify the relative role of intensification and shift in the winds on ventilation of the thermocline in this model, and test the linearity of the response. These simulations are also used to examine the relative role of different processes (e.g., movement of isopycnals and along-isopycnal transport) in causing changes in the age.

The model and experiments are described in section 2 . In section 3 we examine the ideal age response, while in section 4 we examine the causes of the age changes. The model results are compared with observations in section 5 , and concluding remarks are in section 6 .

\section{Model and simulations}

The global ocean-sea ice model and wind perturbations used in this study are those described in Spence et al. (2014), Hogg et al. (2017), and Downes et al. (2017), and are only briefly reviewed here. The ocean component is the National Oceanic and Atmospheric Association Geophysical Fluid Dynamics Laboratory Modular Ocean Model, version 5 (MOM5; Griffies 2012) with $1 / 4^{\circ}$ horizontal resolution and 50 unevenly spaced vertical levels in a geopotential depth coordinate. The model does not include any parameterization scheme for eddy tracer fluxes (i.e., there is no Gent-McWilliams skew diffusion or along-isopycnal "Redi" diffusivity). However, there is a lateral biharmonic Smagorinsky viscosity, parameterized submesoscale effects and vertical diffusivity via KPP and tidal mixing (with background vertical diffusivity set to zero). See Griffies (2012) for details. The ocean component is coupled to the SIS sea ice model (Winton 2000), and sea surface salinity is restored to a monthly climatology on a 60-day time scale. The ocean-ice model is forced by annually repeating atmospheric fluxes derived from version 2 of the Coordinated Ocean-Ice Reference Experiments-Normal Year Forcing (CORE-NYF) reanalysis data (Large and Yeager 2009).

Four model runs are assessed, which differ only in the applied wind stress over the Southern Hemisphere midand high latitudes. The control case is spun up for 500 years, and then used as the initial state for three sensitivity experiments with perturbations to the winds: 1 ) a $30 \%$ increase in the strength of the $10-\mathrm{m}$ wind speed [referred to, as in Hogg et al. (2017), as the "strong" simulation], 2) a $4^{\circ}$ poleward shift of the winds ("shift"), 
(a)

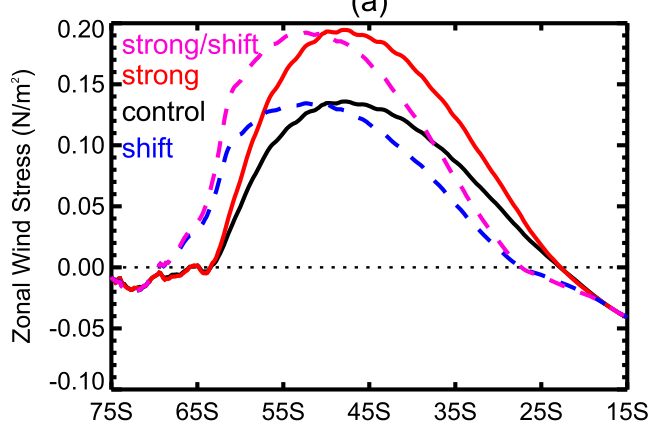

(c) control

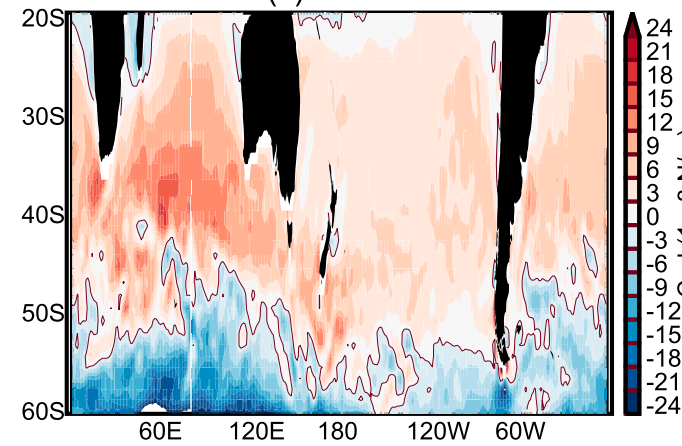

(e) shift-control

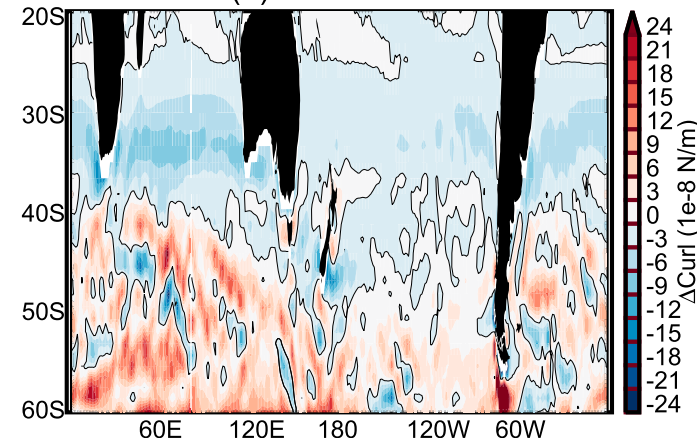

(b)

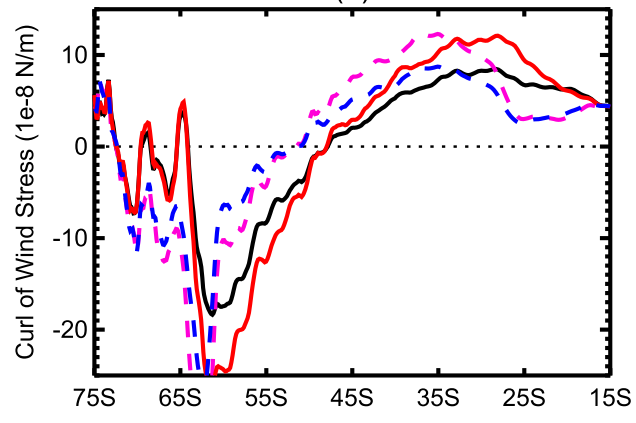

(d) strong-control

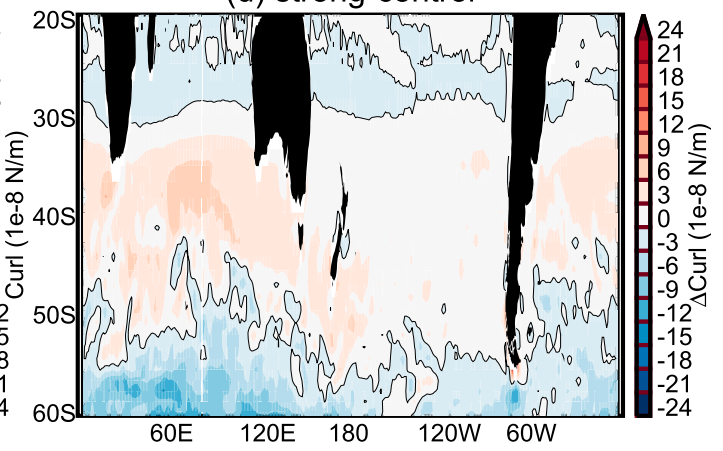

(f) strong/shift-control

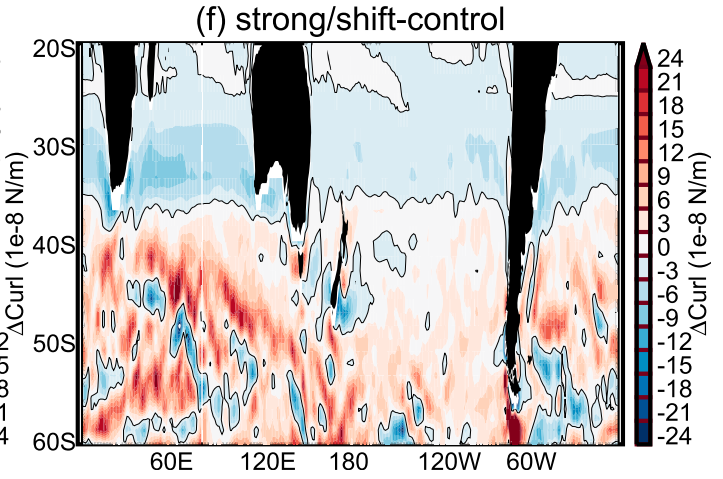

FIG. 1. Zonal-mean (a) wind stress and (b) curl of wind stress for the four simulations, (c) map of wind stress curl $\left(10^{-8} \mathrm{~N} \mathrm{~m}^{-1}\right)$ for the control simulation, and (d)-(f) maps of difference in wind stress curl $\left(10^{-8} \mathrm{~N} \mathrm{~m}^{-1}\right)$ from the control simulation for the strong, shift, and strong/shift simulations, respectively. All fields are decadal means over years 40-49 after the perturbation.

and 3) a combined $30 \%$ intensity increase and $4^{\circ}$ poleward shift ("strong/shift"). The wind anomalies are applied in the $70^{\circ}-25^{\circ} \mathrm{S}$ latitude range and are held fixed throughout the 60 -yr perturbation simulations. The control simulation is also run for an additional 60 years.

In the control simulation the maximum zonal-mean westerly wind stress is $0.13 \mathrm{Nm}^{-2}$ and peaks around $52^{\circ} \mathrm{S}$; see Fig. 1a. As the wind stress is calculated from 10-m winds using the CORE bulk formulas the increase in wind stress for the perturbations is larger than that for the wind speed. The $30 \%$ increase in the $10-\mathrm{m}$ winds in the strong simulation results in a $\sim 40 \%$ increase in the peak wind stress (to $0.19 \mathrm{~N} \mathrm{~m}^{-2}$ ), while the $4^{\circ}$ poleward shift in the peak $10-\mathrm{m}$ winds in the shift simulation results in a $\sim 2.5^{\circ}$ poleward shift in the peak wind stress, see Fig. 1a. The magnitude and location of the peak wind stress in the strong/shift simulation are similar to the projected change by 2100 for "business as usual" emissions scenario (Spence et al. 2014). The above changes in wind stress result in changes in the curl of the wind stress: There is an increase in between $30^{\circ}$ and $50^{\circ} \mathrm{S}$ and a decrease south of $\sim 50^{\circ} \mathrm{S}$ for the strong simulation (Figs. 1b,d), whereas for the shift and strong/shift simulations the wind 
stress curl decreases between $30^{\circ}$ and $40^{\circ} \mathrm{S}$ and increase south of $\sim 40^{\circ} \mathrm{S}$ (Figs. 1b,e,f).

The wind stress perturbations shown in Fig. 1 lead to changes in the surface heat and freshwater fluxes, the mixed layer depth (MLD), and in subduction rates. These changes are documented in Downes et al. (2017), where it is shown that there are substantial spatial variations, with the sign of the changes in different properties varying regionally within the same perturbation runs, as well as between perturbations.

All simulations include an ideal age tracer. For simplicity we shall from now on refer to the ideal age tracer simply as the "age". This age is set to zero in the model surface layer (which is $10 \mathrm{~m}$ thick) at each time step, increases by $1 \mathrm{yr} \mathrm{yr}^{-1}$ within the ocean interior, and is advected and diffused as other tracers (e.g., temperature and salinity). In the limit of long times compared to the circulation, the age equals the mean time since water last made surface contact (e.g., England 1995; Hall and Haine 2002). Unfortunately, age was not archived with other model fields and is only available for three restart files. For all three perturbations the first two restart files are at 25 and 50 years after the perturbation, with the third at 60 years for the strong simulations and 65 years for the shift and strong/shift simulations.

One possible concern with the use of age from restart files is that these files contain only instantaneous fields. However, while this may be an issue for some fields it is not an impediment to assessing patterns of age as it is a quantity which implicitly integrates circulation changes over time. We have confirmed this by comparing age restart fields and annual-mean fields of a newer control run where the ideal age tracer was archived. The differences between restart and annual-mean files are small, except very near the surface where there are higher-frequency variations in the mixed layer depth and the age field.

As we only have the age field for three times after the perturbation was applied we cannot examine the full evolution of the age response. There will not be an instantaneous response to the abrupt wind stress change, and in many regions the age will not yet be in steady state at the end of the simulations (i.e., the age will still be responding to the abrupt perturbations). However, analysis of the data we have indicates that the age response in mode and intermediate waters is close to the equilibrium response 50 years after the perturbation (see section 3a below).

We focus our analysis on the age after 50 years. For all four simulations there is a restart file for 1 January 50 years after the perturbations were applied. For dynamical fields, we use the average either over years $40-49$ or over year 50 depending on field and purpose of analysis

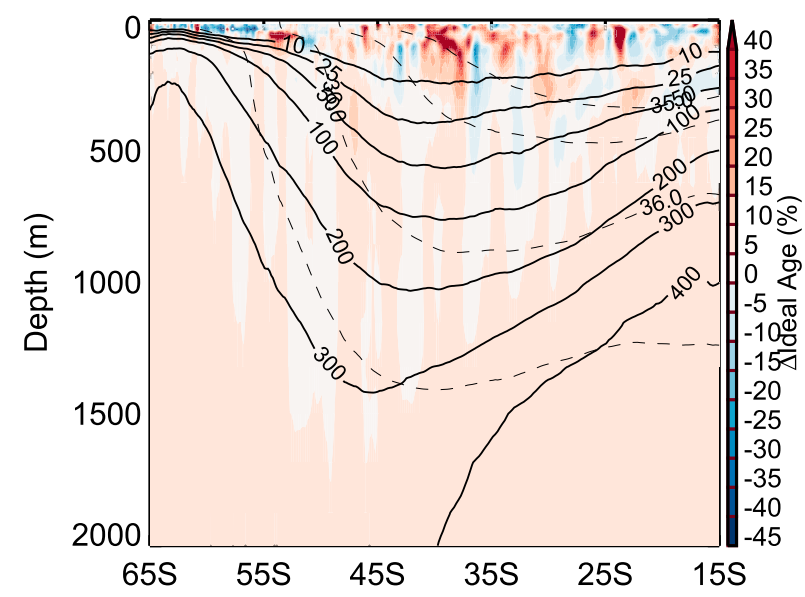

FIG. 2. Zonal-mean ideal age at year 550 from the control simulation (contours) and change in age between years 500 and 550 (shading). Dashed contours show the $\sigma_{2}=35.0,35.5,36.0$, and $36.5 \mathrm{~kg} \mathrm{~m}^{-3}$ surfaces.

(discussed further below when data are presented). The response of the various fields examined is determined as the difference between the wind perturbation simulations and the concomitantly extended control simulation (i.e., the response of the age in the strong perturbation is $\Delta \alpha_{\text {strong }}=a_{\text {strong }}-a_{\text {control }}$, where $a_{\text {strong }}$ and $a_{\text {control }}$ are the ideal age from the strong and control simulations, respectively, evaluated at the same year). This approach reduces the effects of any model drift.

\section{Ideal age response}

Before examining how the age changes in response to the different wind stress perturbations we examine the age distribution from the control run. The solid contours in Fig. 2 show the zonal-mean age at year 550 in the control simulation (which is 50 years after the perturbation was applied in the perturbation simulations). As the simulation has only been run for 550 years the age is not in steady state and is still increasing, especially for older waters in the deep ocean. However, as shown by color shading in Fig. 2, the change in age between years 500 and 550 is small. Specifically, the changes in age within SAMW and AAIW, which correspond roughly to $35.5<\sigma_{2}<36.0 \mathrm{~kg} \mathrm{~m}^{-3}$ and $36.0<\sigma_{2}<36.5 \mathrm{~kg} \mathrm{~m}^{-3}$, respectively, are generally less than $5 \%$. Thus, the $500-y r$ spinup is long enough for our analysis of age changes in SAMW and AAIW.

The ideal age distribution in Fig. 2 shows the downward penetration of young water masses in the subtropical thermocline (e.g., ages less than 100 years at $500-\mathrm{m}$ depth and $40^{\circ} \mathrm{S}$ ) and the upwelling of old, deep water in subpolar ocean (e.g., ages greater than 300 years 

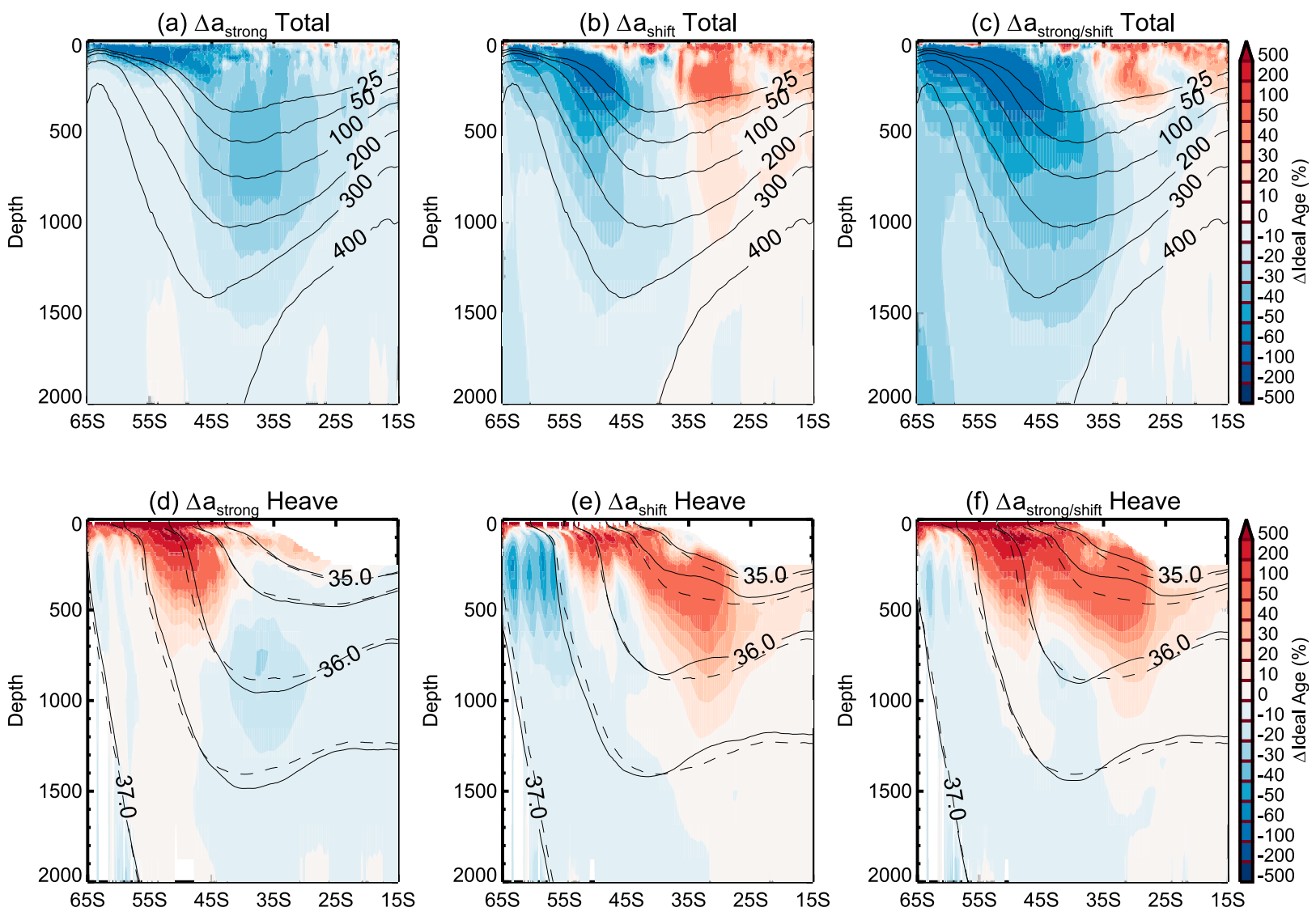

(g) $\Delta \mathrm{a}_{\text {strong }}$ Isopycnal
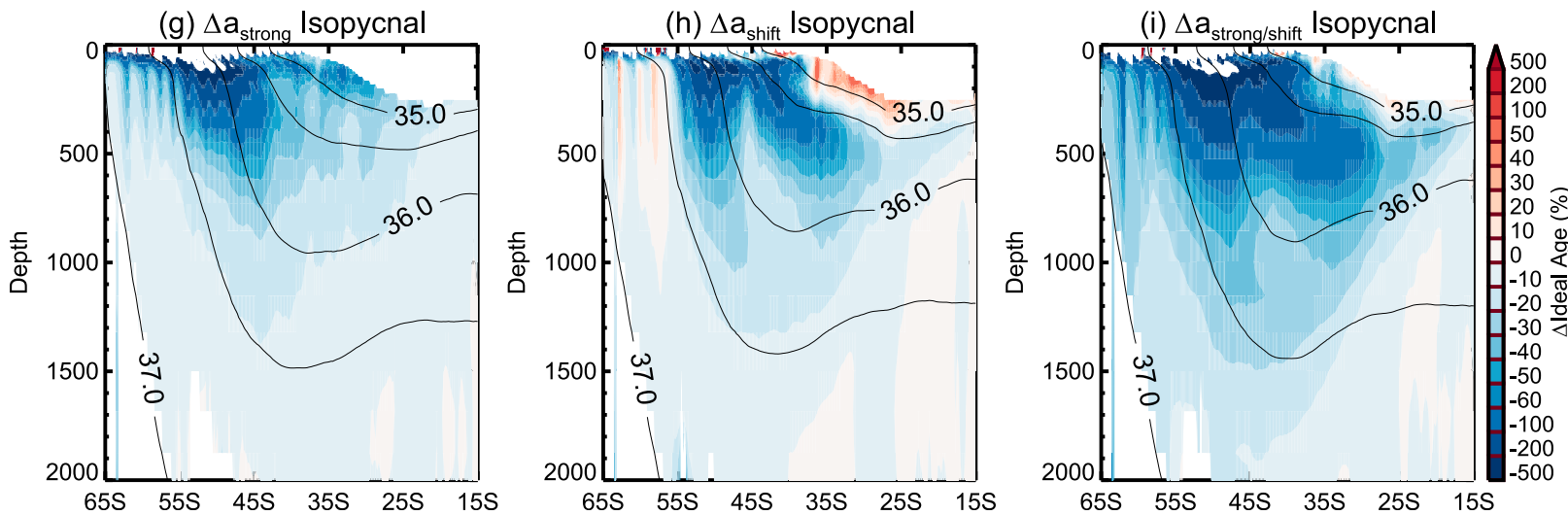

FIG. 3. Percentage difference in zonal-mean $\Delta a$ for (a),(d),(g) strong, (d),(e),(h) shift, and (c),(f),(i) strong/shift simulations for 50 years after the perturbation. (a)-(c) Total change, (d)-(f) change due to heave, and (g)-(i) change on isopycnal surfaces. Solid contours in (a)-(c) show ideal age from control runs and in (d)-(i) show potential density for perturbation simulations. Dashed contours in (d)-(f) show potential density for the control simulation.

at $500-\mathrm{m}$ depth and $60^{\circ} \mathrm{S}$ ). This age distribution is consistent with observational-based estimates of the ideal age (e.g., Fig. 11 of DeVries and Primeau 2011).

We now examine the age tracer in the perturbation simulations 50 years after the perturbations were applied. We focus first on changes in the zonal-mean age, and then consider the horizontal structure of age on isopycnal surfaces.

\section{a. Zonal mean}

The changes in zonal-mean age in the (Fig. 3a) strong $\left(\Delta a_{\text {strong }}\right)$, (Fig. 3b) shift $\left(\Delta a_{\text {shift }}\right)$, and (Fig. 3c) strong/ 
shift $\left(\Delta a_{\text {strong/shift }}\right)$ simulations, expressed as a percentage of the control age, are shown in Figs. 3a-c. In all three perturbations $\Delta a<0$ within the thermocline, but the magnitude and spatial structure of the age changes vary. In the strong simulation $\Delta a<0$ throughout the upper subtropical waters $\left(55^{\circ}-25^{\circ} \mathrm{S},>1000 \mathrm{~m}\right)$ but in both the simulations involving a shift in the peak winds $\Delta a>0$ north of around $35^{\circ} \mathrm{S}$. While the spatial structure differs, the magnitude of the $\Delta a$ in the strong and shift simulations are comparable, with peak decreases around 50 years. The decrease in age south of $35^{\circ} \mathrm{S}$ is larger in the strong/shift simulation than in the shift simulation, and the structure and magnitude of $\Delta a_{\text {strong/shift }}$ is similar to the sum of $\Delta a_{\text {strong }}$ and $\Delta a_{\text {shift }}$.

The similarity of $\Delta a_{\text {strong/shift }}$ to the sum of $\Delta a_{\text {strong }}$ and $\Delta a_{\text {shift }}$ suggests weak nonlinearity. To quantify this, we calculate the difference $\Delta a_{\text {nonlinear }}=\Delta a_{\text {strong/shift }}-$ $\left(\Delta a_{\text {strong }}+\Delta a_{\text {shift }}\right)$, which corresponds to the nonlinear interaction between a strengthening and shift in the wind stress (e.g., Stein and Alpert 1993). The left side of Fig. 4 shows $\Delta a_{\text {strong }}+\Delta a_{\text {shift }}$ after 25 (Fig. 4a), 50 (Fig. 4c), and 65 years (Fig. 4e), while the right side shows $\Delta a_{\text {nonlinear }}$ for the same times. (The age for the strong simulation is only available at 60 years and not 65 years after the perturbation as in the other two perturbations, and we have used this for the " 65 year" analysis.) For all three years $\Delta a_{\text {nonlinear }}$ is around or less than $5 \%$ through most of the SAMW and AAIW (right side of Fig. 4), indicating that the age response is close to linear. ${ }^{1}$ There is a region near the surface with large percentage nonlinear interaction, but the age is very small in this region meaning that a small difference corresponds to a large percentage difference.

Figure 4 not only shows the linearity of the response but also provides insight into the temporal evolution of the response. The spatial structure of $\Delta a_{\text {strong/shift }}$ (or sum of $\Delta a_{\text {strong }}$ and $\left.\Delta a_{\text {shift }}\right)$ is very similar for 25, 50, and 65 years after the perturbation, with $\Delta a_{\text {strong/shift }}<0$ in SAMW and AAIW between $35^{\circ}$ and $55^{\circ} \mathrm{S}$, and $\Delta a_{\text {strong/shift }}>0$ in upper waters north of $35^{\circ} \mathrm{S}$. The magnitude of the

\footnotetext{
${ }^{1}$ Figure 4 shows that the sum of the individual forcing is very close to the combined forcing simulation, and hence that the response satisfies the additivity property [i.e., $f(x+y)=f(x)+f(y)$, where $f(x)$ is the response to perturbation $x]$. If the response is linear, then it must also satisfy the homogeneity property [i.e., $f(c x)=c f(x)]$. We do not have a simulation to explicitly test the homogeneity, but note that additivity is strong evidence of linearity. In fact, for smooth functions $f(x)$ additivity guarantees homogeneity (and hence linearity) for real numbers $c$ in $f(c x)=c f(x)$. For nonsmooth $f(x)$ additivity guarantees homogeneity for rational numbers $c$, which is only slightly more restrictive. For these reasons, the evidence we present, while not rising to the level of a mathematical proof, strongly suggests the age response is linear.
}

decrease or increase in these waters grows with time, but the change between years 50 and 65 is small (e.g., within SAMW and AAIW the magnitude of the difference is generally less than $2 \%$, with only a few localized regions where it reaches $5 \%$ ). Similar small differences are found between years 50 and 65 for individual perturbation simulations. This result suggests that $\Delta a$ in AAIW and lighter waters after 50 years is generally close to the equilibrated response. Analysis of the evolution of age from the CCSM abrupt wind stress examined in Waugh (2014) shows a similar result: in these runs the change in age in SAMW and AAIW after 50 years is at least $80 \%$ of the change after 100 years.

While our focus is on $\Delta a$ within SAMW and AAIW there are substantial changes in age in the Southern Ocean (south of $60^{\circ} \mathrm{S}$ ) (see Fig. 3). In particular, for perturbations where there is a shift in the winds there is a large decrease in the age of Antarctic Bottom Water $(\mathrm{AABW})$ and Circumpolar Deep Water (CDW), with $\Delta a<-100 \mathrm{yr}$ at the sea floor. This is related to the formation of an open-ocean polynya and increased production of dense water in the Weddell Sea in these simulations (Hogg et al. 2017). Given the transient nature of the response (Hogg et al. 2017) and limited age output available we do not examine these age changes. However, we do note that the linearity of the age response in SAMW and AAIW discussed above does not hold in the abyssal Southern Ocean; that is, the decrease of age in $\mathrm{AABW}$ and CDW in the strong/shift perturbation is larger than the sum of the responses for the individual strong and shift perturbations.

The change in age shown in Figs. $3 \mathrm{a}-\mathrm{c}$ is due to a combination of processes, including the wind-driven movement of isopycnals ("heave"; Bindoff and Mcdougall (1994)), change in transport (advection and stirring) along isopycnals, and diapycnal mixing. To estimate the role of heave in the age changes $\Delta a_{\text {heave }}$ (for simplicity we drop the name of the perturbation), the zonal-mean age in latitude-density space from the control simulation is mapped into latitude-depth space using the density-depth relationship from a perturbation simulation. A similar approach is used to isolate the isopycnal transport $\Delta a_{\text {isopyncal }}$ : we calculate the age change at fixed potential density between the perturbation and control simulations, and then map this change back to depth space using the density distribution from the control simulation.

We first consider the spatial structure of $\Delta a_{\text {heave. As }}$ shown in Figs. 3d-f, for all three perturbations the sign of $\Delta a_{\text {heave }}$ varies within SAMW and AAIW. As the age generally increases with depth, an upward movement of isopycnals causes an increase in the age at fixed depth, with the reverse for a downward movement. In the 

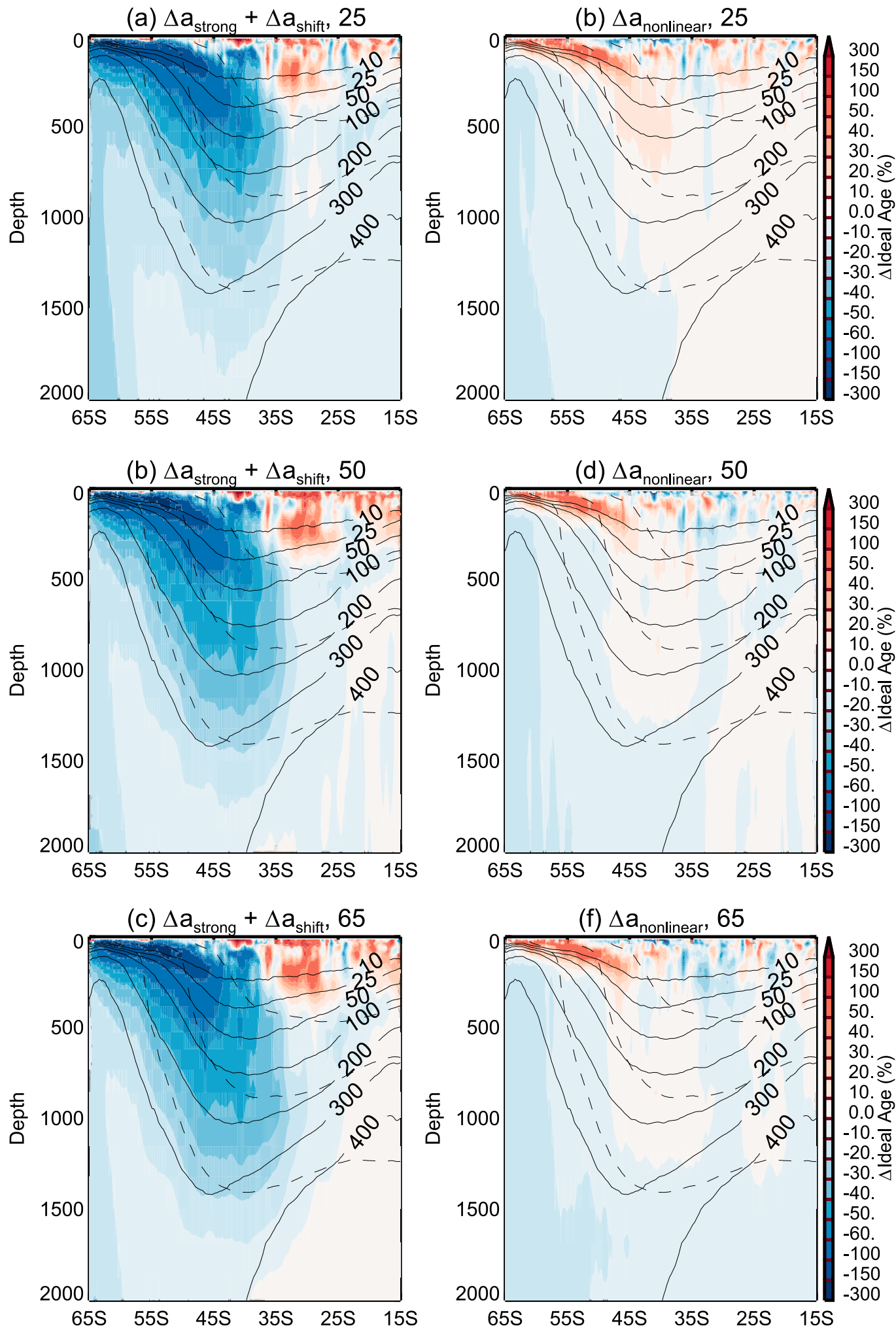

FIG. 4. As in Fig. 3a, but for (a),(c),(e) sum of $\Delta a_{\text {strong }}$ and $\Delta a_{\text {shift }}$, and (b),(d),(f) $\Delta a_{\text {nonlinear }}$ (see text) for years (top) 25 , (middle) 50 , and (bottom) 65 after the perturbation. 
strong simulation, the isopycnals deepen between $25^{\circ}$ and $45^{\circ} \mathrm{S}$ but they shoal between $50^{\circ}$ and $55^{\circ} \mathrm{S}$ (cf. solid and dashed curves in Fig. 3d), consistent with the increase in wind stress curl north of $55^{\circ} \mathrm{S}$, the decrease south of $45^{\circ} \mathrm{S}$ (Fig. 1b), and the resulting change in Ekman pumping. This movement of isopycnals then results in $\Delta a_{\text {heave }}<0$ between $25^{\circ}$ and $45^{\circ} \mathrm{S}$ and $\Delta a_{\text {heave }}>0$ between $50^{\circ}$ and $55^{\circ} \mathrm{S}$, in the strong simulation (Fig. 3d). The vertical movement of isopycnals north of $40^{\circ} \mathrm{S}$ in the shift and strong/shift simulations is opposite to that in the strong simulation (again consistent with changes in the wind stress curl shown in Fig. 1b), and thus an opposite sign in $\Delta a_{\text {heave }}$.

In contrast, the sign of $\Delta a_{\text {isopycnal }}$ (Figs. 3g-i) is the same for all perturbations (i.e., $\Delta a_{\text {isopycnal }}<0$ for $35.5<$ $\left.\sigma_{2}<36.5 \mathrm{~kg} \mathrm{~m}^{-3}\right)$. The magnitude of $\Delta a_{\text {isopycnal }}$ is similar for the strong and shift perturbations, but there are differences in the spatial structure: For the strong perturbation the largest percentage decrease is centered around $\sigma_{2}=36 \mathrm{~kg} \mathrm{~m}^{-3}$ (boundary between SAMW and AAIW) whereas for the shift perturbation there is a local minimum around $\sigma_{2}=36 \mathrm{~kg} \mathrm{~m}^{-3}$. Consistent with the above discussion of linearity, $\Delta a_{\text {isopycnal }}$ for the strong/shift perturbation is similar to the sum of the strong and shift perturbations.

In all perturbations, addition of $\Delta a_{\text {heave }}$ and $\Delta a_{\text {isopyncal }}$ produces changes in age that are very similar to the directly simulated total change $\Delta a_{\text {total }}$ shown in Figs. 3a-c [i.e., for most of SAMW and AAIW the sum of the percentage change for $\Delta a_{\text {heave }}+\Delta a_{\text {isopyncal }}$ is within $1 \%$ of $\Delta a_{\text {total }}$ (not shown)]. This means that the impact of diapycnal mixing on the age response is generally small. There are regions where $\Delta a_{\text {heave }}$ and $\Delta a_{\text {isopycnal }}$ are the same sign change in age (e.g., both cause a decrease in age around $1000 \mathrm{~m}, 35^{\circ} \mathrm{S}$ in the strong simulation), as well as regions where they oppose each other, including regions where $\Delta a_{\text {total }} \approx 0$ due to near complete cancelation between $\Delta a_{\text {heave }}$ and $\Delta a_{\text {isopycnal }}$ (e.g., 200-500 m, $30^{\circ} \mathrm{S}$ in the strong simulation). In the strong simulation the two processes act together through most of the SAMW and AAIW, whereas the processes tend to oppose each other in the perturbations involving a shift in the winds.

\section{b. Horizontal structure}

The above analysis has focused on change in zonalmean age, but the response may vary between oceans (or zonally within an ocean basin). So we now examine the horizontal patterns of the age and its response to the perturbations. We focus on distributions on isopycnal surfaces, and for simplicity show the age (or difference in age) only on the $\sigma_{2}=36 \mathrm{~kg} \mathrm{~m}^{-3}$ surface. The $\sigma_{2}=$ $36 \mathrm{~kg} \mathrm{~m}^{-3}$ surface is approximately the boundary between the SAMW and AAIW water masses, and the changes shown are representative of those on other isopycnals containing mode and intermediate waters.

Considering first the age distribution in the control simulation. The age increases with distance away from the outcrop in each ocean basin (Fig. 5a). However, there are differences between oceans. The age in the subtropical Pacific Ocean is greater than in the other basins (at same latitudes or same distance from outcrop). Furthermore, the youngest water in the Pacific (excluding coastal regions) occurs on the eastern edge of the basin but in the Atlantic Ocean the youngest water is in the western side of the basin. These differences in age between basins are also found in the age estimated from CFC11 measurements [e.g., Fig. 5 of Fine et al. (2017)].

The general structure of the age on the $\sigma_{2}=36 \mathrm{~kg} \mathrm{~m}^{-3}$ surface in the strong simulation is very similar to that in the control, except that there is a decrease in age $\left(\Delta a_{\text {strong }}<0\right)$; see Fig. 5 b. (Note, as the age is very small near outcrops, we show the absolute change in age in Figs. $5 b-d$, rather than percentage change shown in Fig. 3.) $\Delta a_{\text {strong }}$ is similar in each ocean basin, with a fairly uniform decrease of around 20 years at mid- and lower latitudes, and limited zonal variations. In both the shift and strong/shift simulations there is more spatial structure in $\Delta a$; see Figs. $5 \mathrm{c}$ and $5 \mathrm{~d}$. This includes large decreases $(\Delta a<-50$ years $)$ in age along the eastern edge of the Pacific Ocean and across the Pacific around $30^{\circ} \mathrm{S}$, and little change or an increase in the age throughout most of the South Atlantic in the shift simulation. The causes of these changes are discussed in section 4 below.

In all three perturbations there is zonal variability near the surface outcrop, with localized regions with decreases or increases in age. The variability in age changes near the outcrop is especially prominent in the shift simulation, where a region of large increase $(\Delta a>$ 50 years) occurs around $30^{\circ}-60^{\circ} \mathrm{W}$ and regions of similarly large decreases $(\Delta a<-50$ years $)$ occur around $90^{\circ}-120^{\circ} \mathrm{W}$ and $100^{\circ}-140^{\circ} \mathrm{E}$.

\section{c. Volume of young waters}

As the spatial variations in the change in age differ between perturbations, it is useful to compare the change in integrated measures of the ventilation age. One such measure is the volume of water with ideal age less than a specified value. This metric has been used in previous modeling studies of changes in ventilation (e.g., Russell et al. 2006; Gnanadesikan et al.2007), and can be used to provide some insights into changes in ocean uptake of anthropogenic heat and carbon.

Figure 6a shows the differences between the perturbation and control simulations in volume of water 
(a) control

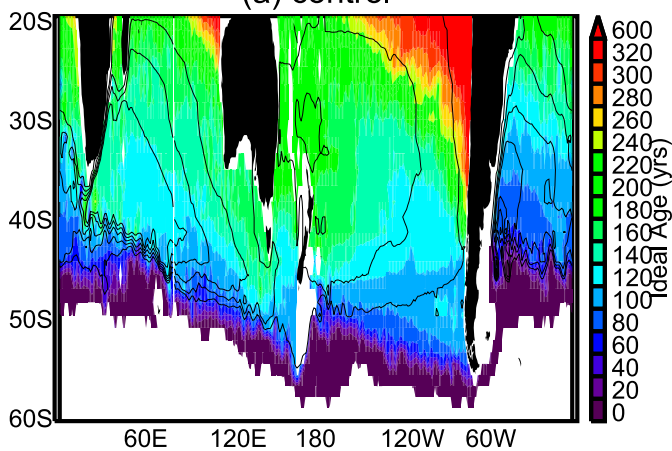

(c) shift-control

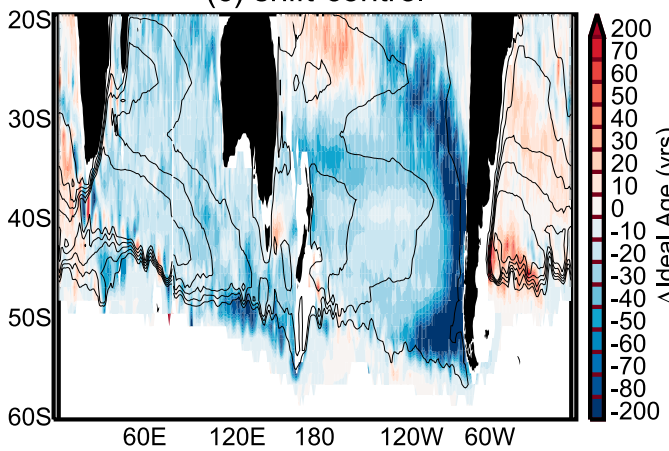

(b) strong-control

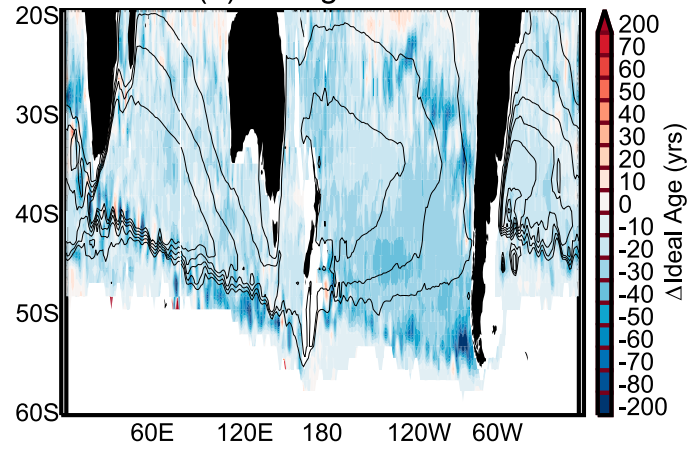

(d) strong/shift-control

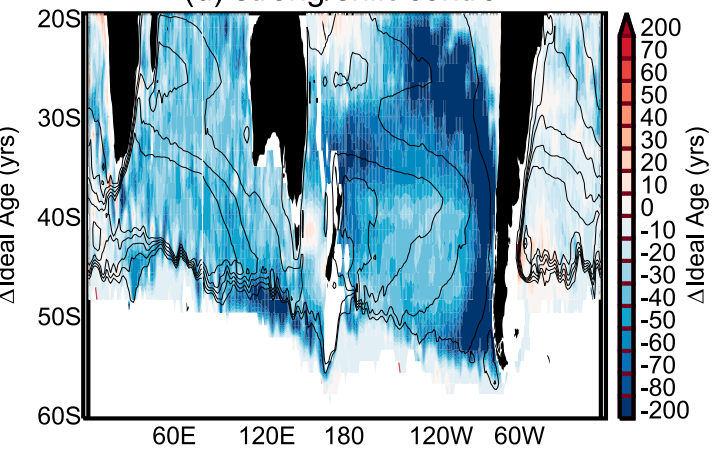

FIG. 5. Maps of (a) age for the control and difference in age between (b) strong, (c) shift, and (d) strong/shift simulations and the control simulation on the $\sigma_{2}=36 \mathrm{~kg} \mathrm{~m}^{-3}$ surface. Contours show barotropic streamfunction for $0,-10,-20,-30$, and $-40 \mathrm{~Sv}$.

between $10^{\circ}$ and $60^{\circ} \mathrm{S}$ for age less than values given on the $x$ axis (we show only ages less than 250 years as this is the water contained in AAIW or lighter waters; see Fig. 1). There is a $10 \%-15 \%$ increase in the volume of young water for the strong simulation, with slightly larger increases for volume of the youngest ages (less than $\sim 50$ years). There is more sensitivity of the change in volume to the upper age limit for the perturbations involving a shift in the winds. Specifically, for the shift simulation there is a decrease in volume if considering only water younger than 50 years, no change in volume of water less than 50 years, and an increase in volume of water with ages more than 50 years. For the strong/shift simulation there is an increase in the volume of water for all age classes less than 250 years, but the percentage change increases with upper age, from less than $10 \%$ for the youngest ages to over $25 \%$ for water with ages less than 200 years. The volume changes in the strong/shift simulation are consistent with above discussion of linearity, close to the sum of the changes from the strong and shift perturbations for ages less than 150 years (see dashed curve). Note, again, our analysis is for 50 years after the perturbation and the age response is still increasing in older waters, so the changes in volume of older waters are likely still increasing, and this may contribute to the lack of linearity for the volume of older waters.
The changes in volume shown in Fig. 6a are consistent with the earlier analysis of the spatial variations of the zonal-mean age. This connection can be seen more clearly by comparing the mean ideal age on isopycnal surfaces. The changes in isopycnal-mean age for $\sigma_{2}=$ $34.5-36.5 \mathrm{~kg} \mathrm{~m}^{-3}$ (and $10^{\circ}-60^{\circ} \mathrm{S}$ ) are shown in Fig. 6b, for each perturbation. This shows a decrease in the isopycnal-mean age of similar magnitude for all densities in the strong simulation. The similarity in magnitude of the mean values is consistent with the similar increase in volume for water of different ages. Figure $6 b$ also shows that in the shift simulation there is an increase in age on isopycnals with $\sigma_{2}<35.25 \mathrm{~kg} \mathrm{~m}^{-3}$ and a decrease in age for denser surfaces for the shift perturbation, again explaining the change in volume of water with different ages (as the youngest ages are found in the lightest layers). Again, the changes in the strong/shift simulation are close to the sum of changes in the other two perturbations (dashed curve in Fig. 6b).

It is possible that the changes in volume of young water shown in Fig. 6a could be due changes in the area of the isopycnal outcrops (and not the rate of transport within mode or intermediate waters). However, for all perturbations the sign of the change in outcrop area varies for isopycnals within SAMW and AAIW, with 


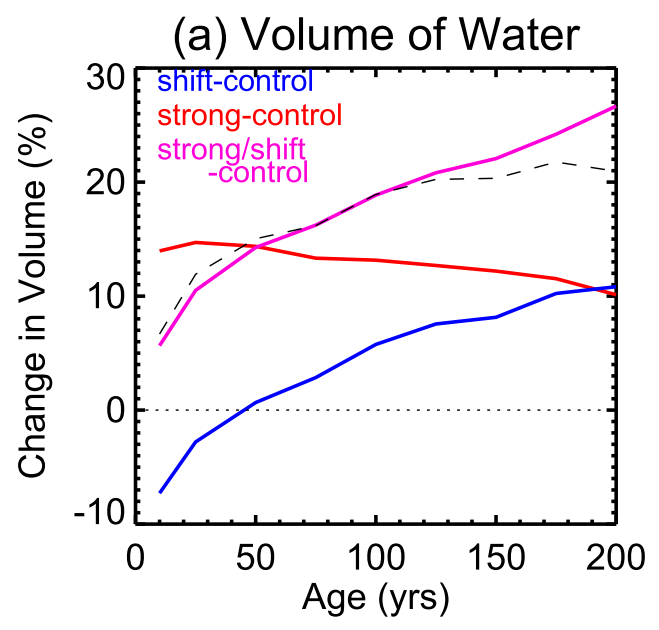

(c) Strong

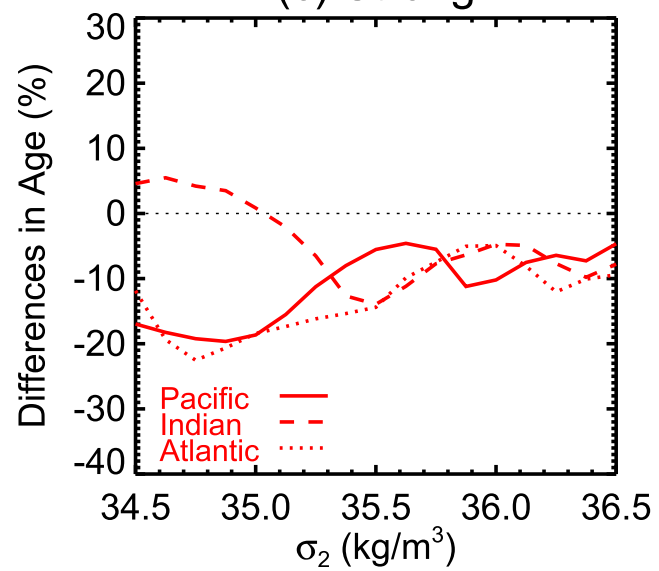

(b) Isopycnal-Mean Age

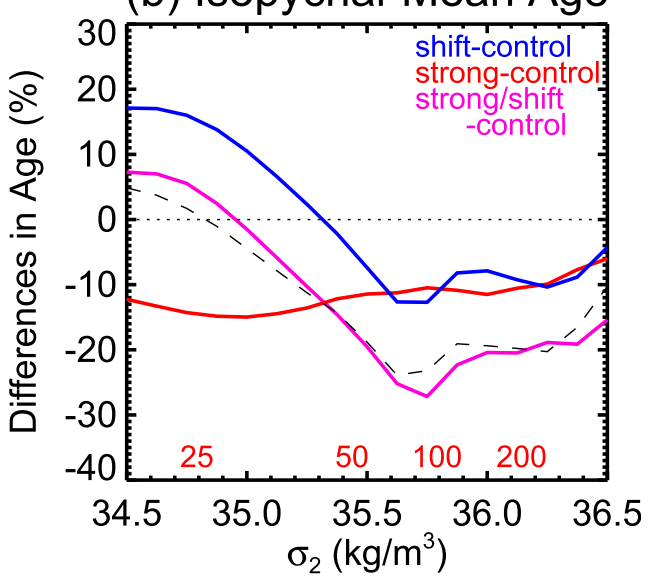

(d) Shift

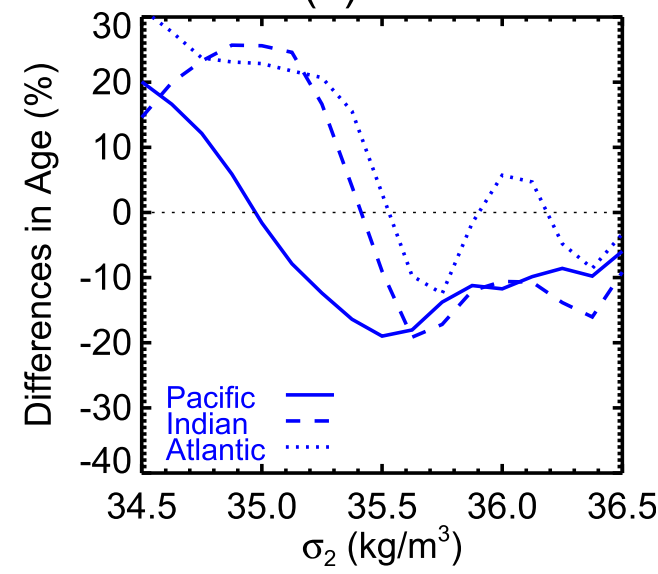

FIG. 6. (a) Change in volume of water with age less than values given on the $x$ axis and (b) difference in isopycnalmean age for the strong, shift, and strong/shift perturbations (differences from the control simulation). The volume and isopycnal-mean are calculated over $10^{\circ}-60^{\circ} \mathrm{S}$. Red numbers in (b) are the mean values of age for the control simulation. Dashed curves show sum of strong and shift perturbations. (c),(d) Difference in isopycnal mean age for the (c) strong and (d) shift from the control simulation for averages over the Pacific, Indian, and Atlantic Oceans $\left(10^{\circ}-60^{\circ} \mathrm{S}\right)$

some showing an increase in area and others showing a similar magnitude decrease. Thus changes in outcrop area cannot explain the increase in the volume of water younger than 100-200 years in all perturbations.

The above analysis focused on the volume of young water and isopycnal-mean age across all southern oceans, but similar results are found for individual basins. In each of the Pacific, Indian, and Atlantic Oceans the volume of water with ages less than 10-250 years increases for the strong perturbation, whereas the volume of waters with ages less than around 50 years decreases for the shift perturbation (not shown). Also, there is a decrease in isopycnal-mean age averaged over each ocean in the strong simulations, except for the lightest waters $\left(\sigma_{2}<\right.$ $35 \mathrm{~kg} \mathrm{~m}^{-3}$ ) in the Indian Ocean (Fig. 5c), while for the shift simulation the isopycnal-mean age decreases in denser waters and increases in lighter waters in each ocean (Fig. 5d). There is, however, some variation between oceans in the density separating isopycnals where the age increases from those where it decreases.

\section{Mechanisms}

We now examine the causes of the changes in age. As shown above, changes in the depth of isopycnals has a large impact on the age at fixed depth. This movement of isopycnals can be related to changes in the wind stress curl and the resulting changes in Ekman pumping. However, it is not clear whether the age changes on each isopycnal surface are due to changes in the tracer transport (advective and mixing) along isopycnals or to changes in the mixing across isopycnals, or what causes the changes in along- or 
(a) control

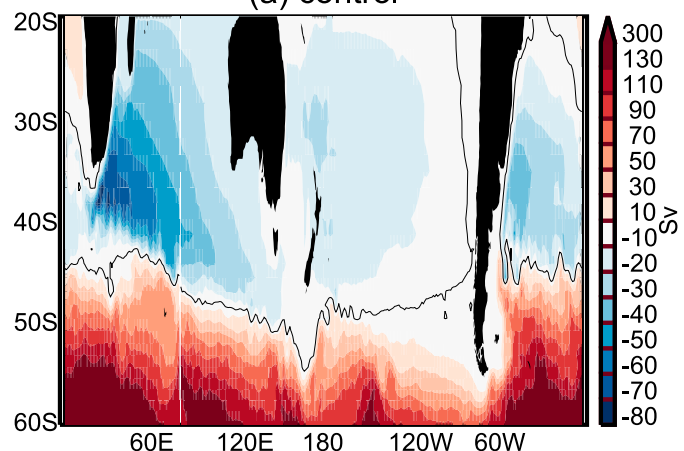

(c) shift-control

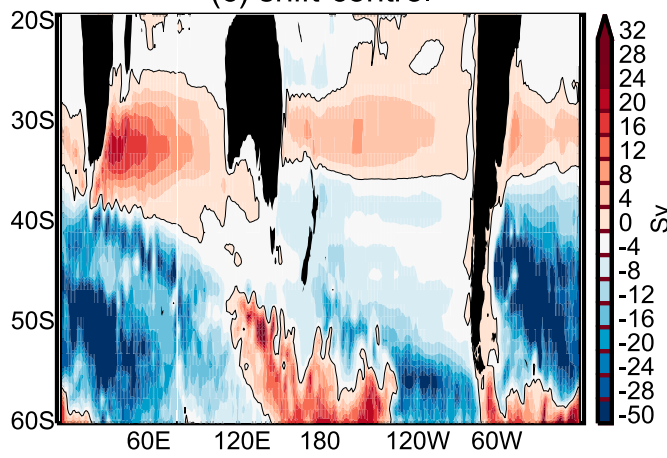

(b) strong-control

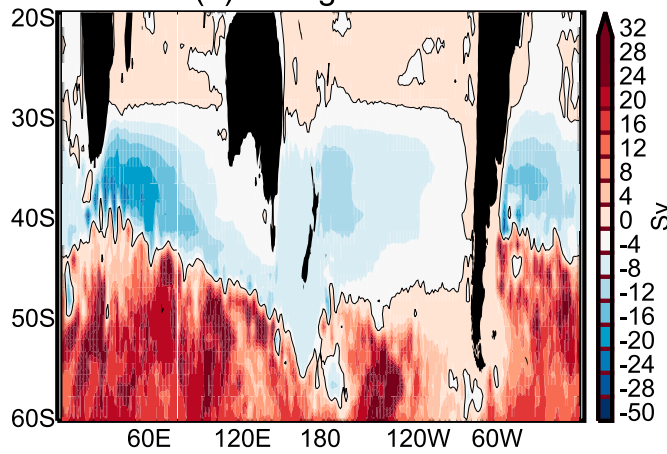

(d) strong/shift-control

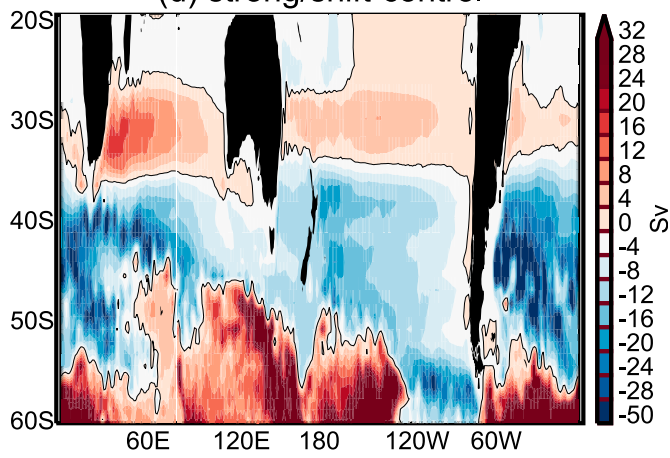

FIG. 7. Maps of barotropic streamfunction (Sv) for (a) the control and the difference between (b) strong, (c) shift, and (d) strong/shift and the control simulation.

across-isopycnal transport. We first examine the possibility that the wind stress perturbations lead to a change in the strength of the mean horizontal circulation, which in turn leads to a changes in along-isopycnal transport and ages within the thermocline.

Changes in the horizontal circulation in the perturbation simulations are examined using the (depthintegrated) barotropic streamfunction (BSF), which is a commonly used indicator of the horizontal subtropical gyre circulation. A stronger BSF would-in the absence of other changes-be expected to lead a stronger circulation on isopycnals, more rapid advection from the surface to the interior along an isopycnal, and a younger age. Insights into how the structure and magnitude of the BSF may change with the wind stress can gained from the Sverdrup relationship:

$$
\Psi(\lambda)=-\int_{\lambda}^{\lambda_{E}} \frac{k \cdot \nabla \times \tau}{\rho \beta} a \cos \phi d \lambda+\Psi\left(\lambda_{E}\right)
$$

where $\Psi$ is the Sverdrup streamfunction, $\tau$ is the wind stress, $\lambda_{E}$ is the eastern longitude of the basin, and standard notations are used for the other symbols. Although $\Psi$ is only an approximation of the BSF (which is calculated from depth-integrated velocities in the model), it provides an indicator of how the BSF may change in response to a change in wind stress. In particular, an increase in the wind stress curl will according to (1) lead to an increase in the peak magnitude of $\Psi$ and an intensification of the southern subtropical gyres (e.g., Saenko et al. 2005, Cai 2006; Cai and Cowan 2007).

The BSF (averaged over years 40-49 after the perturbation) for the control simulation is shown in Fig. 7a, and negative values of BSF (which corresponds to the subtropical gyre) for each simulation are superimposed over the ideal age in Fig. 5. The BSF fields show a closed anticyclonic (subtropical gyre) circulation in each ocean, with the strongest circulation (more negative BSF) in the Indian Ocean and the weakest over the Pacific Ocean.

While there is a similar BSF structure in all simulations (see contours in Fig. 5), there are substantial differences in the magnitude and location of the subtropical gyres between simulations; see Figs. 7b-d. Analysis of the temporal evolution of the BSF shows that it takes 5-10 years for the circulation to "spin up," and that the BSF for years 40-49 after the perturbation is close to steady state. It is therefore reasonable to compare the average BSF for years 40-49 with Sverdrup balance, (1), which assumes steady state.

The differences in BSF in the subtropics between simulations are consistent with the expected differences assuming Sverdrup balance, (1). This can be seen by 
comparing the wind stress curl anomalies in Figs. 1c-f with the corresponding anomalies in BSF in Fig. 7. In subtropical regions where there is an increase in the wind stress curl there is, as expected from (1), an increase in the magnitude of the BSF (i.e., $30^{\circ}-50^{\circ} \mathrm{S}$ in the strong simulation), while in regions with a decrease in wind stress curl there is a decrease in the magnitude of the BSF (i.e., $\sim 30^{\circ} \mathrm{S}$ in simulations with a shift). There is even a quantitative agreement in the changes in BSF and that estimated from the wind stress curl. For example, the peak wind stress curl averaged over years 40-49 increased by around $40 \%$ between the strong and control simulations, and there is a similar increase in the magnitude of the minimum BSF increasing around $40 \%-$ $50 \%$ in each ocean [e.g., minimum value in the Pacific is around $-31 \mathrm{~Sv}\left(1 \mathrm{~Sv} \equiv 10^{6} \mathrm{~m}^{3} \mathrm{~s}^{-1}\right)$ in the strong simulation compared to $-21 \mathrm{~Sv}$ in the control simulation].

We now examine if the changes in horizontal circulation (as diagnosed by the BSF) can explain the changes in ideal age. If we make the very simple assumption that changes in the age are dominated by changes in advection by the horizontal circulation, then the change in age would be inversely proportional to the circulation speed. For the strong simulation the age on the $\sigma_{2}=36 \mathrm{~kg} \mathrm{~m}^{-3}$ surface decreases in each ocean (Fig. 5b), consistent with an increase in magnitude of the BSF in the subtropical gyres (Fig. 7b). Furthermore, the age averaged over $35^{\circ}-40^{\circ} \mathrm{S}$ decreases by around $30 \%$, which is roughly the decrease expected from the above $40 \%$ increase in the circulation (if age is inversely proportional to circulation speed, then the age will scale as $1 / 1.4=$ 0.71 ). Thus, the decrease in age resulting from the increase in wind stress in the strong simulation is consistent with simple expectations based on Sverdrup balance and age being inversely proportional to advective flow speed. This agreement indicates that the eddies in the simulation are either responding linearly with the wind stress or that the nonlinear effects of the eddies and mixing are small.

The patterns of age decrease in the Pacific in the shift and strong/shift simulations are also consistent with the BSF changes, with a region of larger decrease in the age around $30^{\circ}-35^{\circ} \mathrm{S}$ across the Pacific where there is a decrease in wind stress curl and a stronger westward flow in these simulations (Figs. $5 \mathrm{c}$,d and $7 \mathrm{c}, \mathrm{d}$ ).

One region where the change in BSF appears not to explain the change in age on the $\sigma_{2}=36.0 \mathrm{~kg} \mathrm{~m}^{-3}$ surface is in the South Atlantic: In the shift simulation the peak magnitude of BSF in the subtropical South Atlantic is similar to the control run but the age is older throughout most of the gyre, while in the strong/shift simulation the peak magnitude of BSF is larger but ages are similar to the control. However, as discussed below, these changes in age within the gyre may be due to changes in the southern extent of the subtropical gyre rather than its strength.

As discussed above, in all three perturbations there is zonal variability near the surface outcrop, with localized regions where there are relatively larger decreases or increases in age. These correspond to regions where there are large changes in the depth of the $\sigma_{2}=$ $36.0 \mathrm{~kg} \mathrm{~m}^{-3}$ surface (see Fig. 8 which shows the differences in the depth of the $\sigma_{2}=36.0 \mathrm{~kg} \mathrm{~m}^{-3}$ surface for the perturbations). In the strong simulation there is generally a small decrease in the depth of the surface near the outcrop in all basins, whereas in the simulations involving a shift in the winds there are regions near the outcrop with much shallower surfaces in the Pacific and Indian oceans but a large increase in depth in the Atlantic Ocean. This contrast in change in depth of isopycnal surface between the Pacific/Indian Oceans and the Atlantic was also found in wind shift experiments of Sijp and England (2008). Comparing Figs. 5 and 8 we see that regions near the outcrop where there is a deeper isopycnal surface there are older ages on that surface (e.g., east of South America in shift), with the reverse for shallower isopycnals (e.g., west of South America in shift). This is illustrated in Fig. 9 which shows the latitudinal profiles of the age on the $\sigma_{2}=36.0 \mathrm{~kg} \mathrm{~m}^{-3}$ surface (top row) and depth of the $\sigma_{2}=36.0 \mathrm{~kg} \mathrm{~m}^{-3}$ surface (bottom row) in the control and shift simulations for three longitudes (note reversed axes for the age). The isopycnal depth and age follow similar latitudinal variations in each simulation, with large differences in depth and age at fixed latitude (i.e., in the shift simulation there are older ages around $42^{\circ} \mathrm{S}, 40^{\circ} \mathrm{W}$, and younger ages around $52^{\circ} \mathrm{S}, 100^{\circ} \mathrm{W}$ and $50^{\circ} \mathrm{S}, 240^{\circ} \mathrm{W}$ ).

The above correlation between age on an isopycnal surface and depth of the surface occurs because diapycnal mixing plays an important role near the outcrop. While the impact of diapycnal mixing on the age response can be ignored in the ocean interior (as discussed in section 3a), this is not the case near the outcrops. As shown in Fig. 9 there are large vertical age gradients and large vertical movement of isopycnals in the regions of interest. As a result even small diapycnal mixing will cause a large change in the age at fixed density [i.e., the age on an isopycnal surface increases from mixing with much higher ambient values as an isopycnal deepens (and the reverse for a decrease in depth of the isopycnal)].

This mixing in the regions with relatively larger decreases or increases in age near outcrops also causes large changes in the mixed layer depth (MLD) (see Downes et al. 2017). There is a tendency for shallower MLD in regions with a shallower isopycnal (and reverse for deeper isopycnals), and these changes in MLD cause 
(a) control

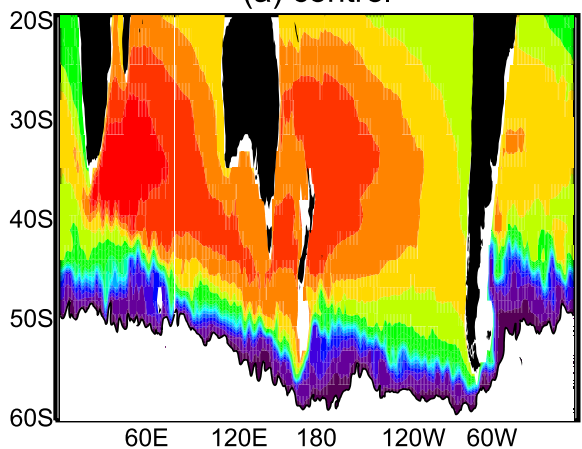

(c) shift-control

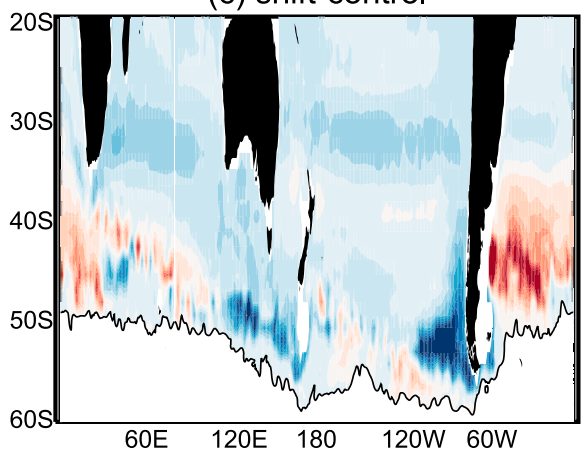

(b) strong-control
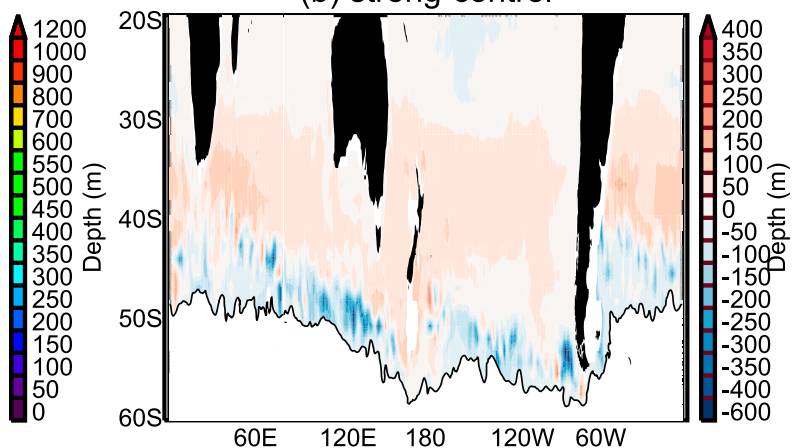

(d) strong/shift-control
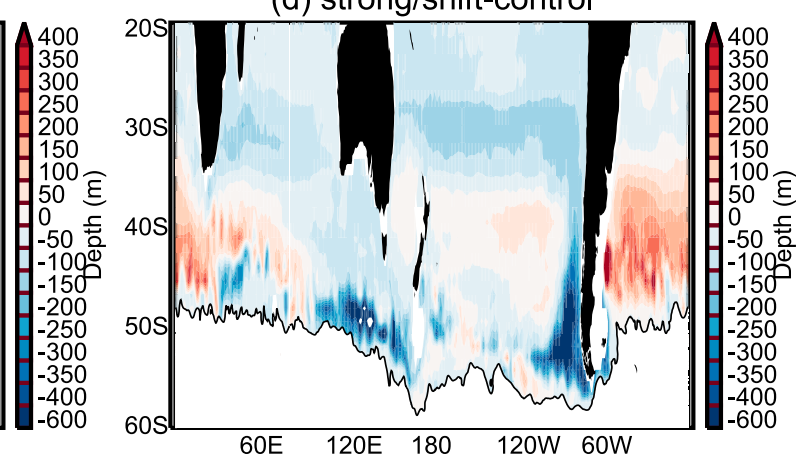

FIG. 8. Maps of depth of the $\sigma_{2}=36 \mathrm{~kg} \mathrm{~m}^{-3}$ surface $(\mathrm{m})$ for (a) the control and the difference between (b) strong, (c) shift, and (d) strong/shift and the control simulations.

changes in the age at depths around the MLD. However, these changes in age are much smaller than the changes in age on isopycnals caused by changes in the depth of an isopycnal (not shown).

In the above we have focused on the impact of changes in the horizontal circulation on changes in the age in SAMW and AAIW, and shown to first order that changes in the age are consistent with changes in the horizontal circulation (and movement of isopycnals) that result from the wind stress changes. However, changes in the MOC may also be playing a role in changes in the age. As mentioned in the introduction, Hogg et al. (2017) examined changes in the MOC and energetics in the same four simulations examined here. They showed that the upper cell of the MOC in densitylatitude space (which is equivalent to the residual or total MOC) is enhanced in the strong simulation but is weaker in the shift and strong/shift simulations. They also note that the change in the MOC strong/shift is close to the superposition of the changes in the strong and shift perturbation, and that there is partial eddy compensation. An enhanced MOC would be expected to lead to younger ages, while a weaker MOC would be expected to lead to older ages. However, for all three perturbations there is a decrease in age due to isopycnal transport. This result suggests that changes in MOC cannot explain the major differences in the response of the age to increases or shifts in the wind stress.

\section{Discussion: Comparison with observations}

The decrease in thermocline age in the wind stress perturbations is qualitatively consistent with estimates from CFC observations that show a decrease in the age of SAMW over a period when there was an increase and poleward shift in the westerly winds (e.g., Waugh et al. 2013; Ting and Holzer 2017). Unfortunately, a detailed quantitative comparison between the simulations and observations is not possible given the idealized nature of the perturbations and the limited age output, that is, the magnitude of the wind stress perturbations in the simulations do not match the observed changes, the perturbations are imposed abruptly in the model whereas in reality the changes in wind stress have occurred more gradually over several decades, with a strong seasonality in the changes, and we do not have the full evolution of the age. In addition there are large uncertainties in the observationally based estimates of the changes in the wind stresses (Swart and Fyfe 2012; Thomas et al. 2015), and age. Nevertheless, some comparisons can be made.

Waugh et al. (2013) calculated a 20\%-30\% decrease in age averaged over SAMW (south of $20^{\circ} \mathrm{S}$ ) from repeat 
(a) Age on $\sigma_{2}=36,40 \mathrm{~W}$

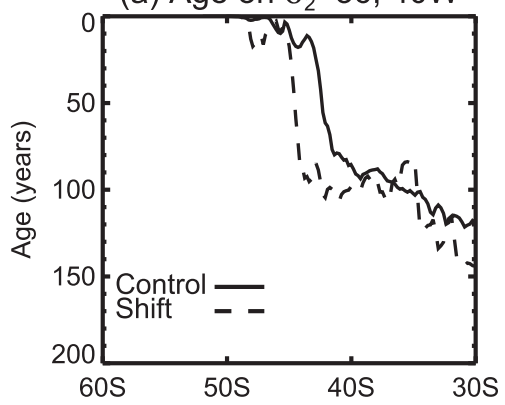

(d) Depth of $\sigma_{2}=36,40 \mathrm{~W}$

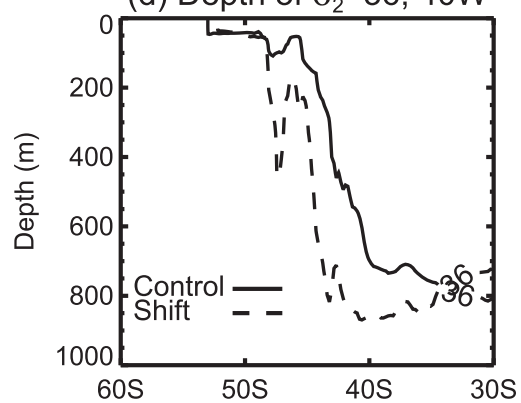

(b) Age on $\sigma_{2}=36,100 \mathrm{~W}$

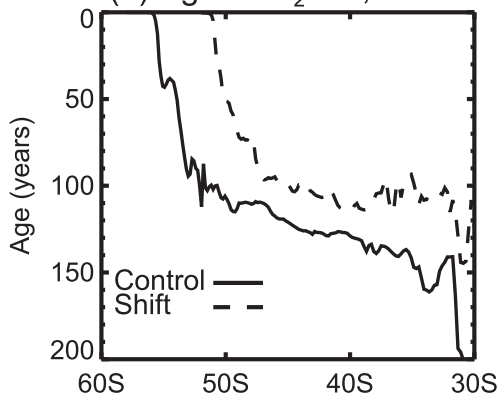

(e) Depth of $\sigma_{2}=36,100 \mathrm{~W}$

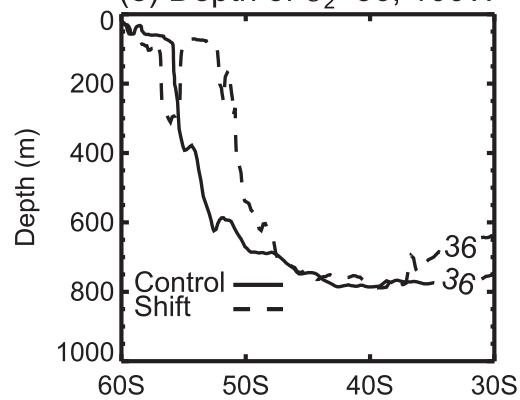

(c) Age on $\sigma_{2}=36,240 \mathrm{~W}$

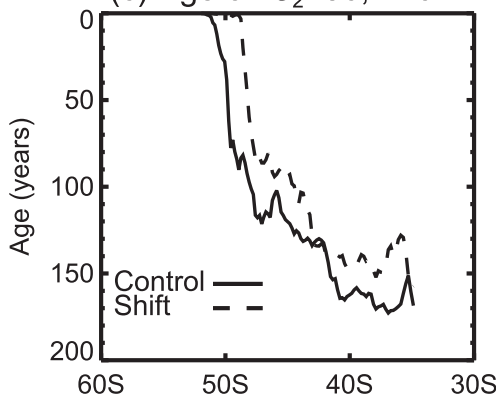

(f) Depth of $\sigma_{2}=36,240 \mathrm{~W}$

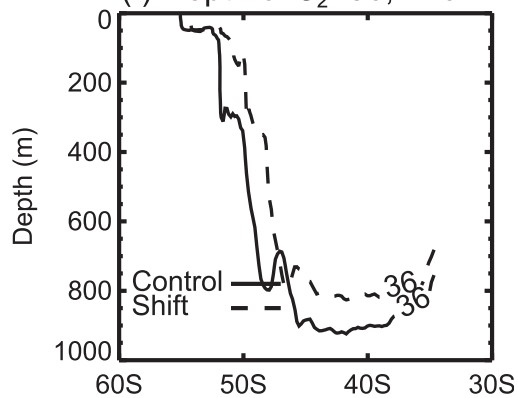

FIG. 9. Latitudinal variations of (a)-(c) age on the $\sigma_{2}=36$ surface and (d)-(f) depth of the $\sigma_{2}=36$ surface along $40^{\circ}, 100^{\circ}$, and $240^{\circ} \mathrm{W}$, for the control (solid) and shift (dashed) simulations. Note the reversed $y$ axis for age.

CFC measurements made in the early 1990s and mid2000s. During and preceding this period there was an intensification and poleward shift in the wind stress for austral summer (December-February). There is large uncertainty in the magnitude of the wind stress changes, with different meteorological reanalyzes yielding different results (Swart and Fyfe 2012; Thomas et al. 2015), but the mean of multiple reanalyses yields around a $15 \%$ increase and a $2^{\circ}$ poleward shift in December-February peak wind stress between 1980 and 2000 .

As these observational estimates of the wind stress changes differ from those used in the simulations a direct comparison cannot be made to see if the above observed changes in wind stress and age are consistent with the model simulations. However, we can take advantage of the fact that the simulated changes in age appear close to linear. For both the strong and shift simulations there is around a $20 \%$ decrease in age averaged over SAMW south of $20^{\circ} \mathrm{S}$ (this is slightly larger than shown in Fig. 6 b, which shows the average from outcrop to $10^{\circ} \mathrm{S}$ ). From this we estimate a $\sim 0.5 \%$ decrease in SAMW age per $1 \%$ increase in peak wind stress (i.e., $\sim 20 \%$ decrease in age from a $40 \%$ increase in wind stress) and an $8 \%$ decrease per $1^{\circ}$ poleward shift (i.e., $\sim 20 \%$ from a $2.5^{\circ}$ poleward shift). Using these estimates we calculate a $23.5 \%$ decrease in age for a combined $15 \%$ increase and $2^{\circ}$ shift in the winds (i.e., $15 \% \times 0.5 \%+2 \% \times 8 \%$ ), which lies within the Waugh et al. (2013) observational estimate of the decrease in age. Thus, the model simulations suggest that the response to changes in the wind stress can explain the majority of the observed changes in age in SAMW, with around two-thirds of the change caused by the poleward shift in the winds and one-third caused by the increase in wind strength. However, we stress again the large uncertainties in the above estimates, and the fact we are comparing a simulated change 50 years after abrupt perturbations with slower real world changes in wind stress.

\section{Summary and conclusions}

Analysis of idealized wind stress perturbations experiments with a global eddy-permitting ocean-ice model indicate that either an increase or a poleward shift in the peak wind stresses over the Southern Ocean leads to a decrease in the ideal age in SAMW and AAIW. The magnitude of the local change in age is similar for a $40 \%$ increase or a $2.5^{\circ}$ poleward shift of the peak winds stress, but there are differences in the spatial structure of the change. In particular, a strengthening of the winds produces a decrease in age throughout the subtropical thermocline, whereas a shift results in decreases in zonal-mean age only south of $35^{\circ} \mathrm{S}$. This results in very different changes in the volume of young water, with an increase in volume with ages less than 
around 50 years for a $40 \%$ increase in the winds but essentially no change in volume for a $2.5^{\circ}$ shift.

The simulated response of the age to changes in the wind stress is close to linear: The response of a combined increase and shift of peak winds is similar to the sum of the individual responses to an increase and a shift. The linearity of the age response is also seen in the success of linear theory in connecting the changes in age to those in the wind stress. The change in age at a fixed location is due to a combination of the movement of isopycnals and changes in the along-isopycnal transport (advection and mixing). The movement of isopycnals (and resulting change in age) is consistent with the changes in the curl of the wind stress, and resulting changes in Ekman pumping (i.e., there is increased downward Ekman velocity, downward movement of isopycnals, and a decrease in age at fixed depth in latitudes where there is an increase in the wind stress curl). At the same time the change in age on isopycnal surfaces is consistent with a linear Sverdrup balance, with an increase in the curl of the wind stress leading to a stronger horizontal circulation and younger ages. This linearity is somewhat surprising as eddies and mixing are expected to change with changing wind stress (e.g., Abernathey and Ferreira 2015), and indicates that in our simulations either the eddies are responding linearly with the wind stress or the nonlinear effects of the eddies and mixing are small.

One consequence of the linearity of the age response is that the results from the strong and shift simulations can be used to estimate the age response for any combination of an increase and shift in the winds. Doing this for observed trends in the wind stress over the last few decades yields changes in the age of SAMW that are consistent with those estimated from CFCs observations (Waugh et al. 2013). Thus, our analysis suggests that the response to changes in the wind stress can explain the majority of recent observed changes in age in SAMW.

The above changes in age in response to wind stress perturbations suggests that these perturbations will impact the oceanic uptake and distribution of anthropogenic heat and carbon. As the majority of the anthropogenic carbon and heat have been produced over the last 50 or so years, changes in the volume of these young waters is particularly relevant for understanding their uptake (Russell et al. 2006). The simulated changes in volume of water with age less than 50 years suggests that the storage of anthropogenic carbon in SAMW and AAIW will increase with a strengthening of the winds, but that there will be much smaller changes for a shift in the peak wind stress. This differing sensitivity of carbon in the upper ocean to an increase or shift in the westerly winds was in fact found in the wind perturbation experiments of D'Orgeville et al. (2010). However, there may not be a one-to-one correspondence between changes in ideal age and anthropogenic heat or carbon, as the response depends on the respective spatial gradients of the field and air-sea exchange and other processes impacting the mixed layer concentrations of the tracers (e.g., solubility for carbon). Further research is planned using abrupt wind stress simulations with ocean biogeochemistry to explicitly examine the carbon uptake and the relationship between changes in age and anthropogenic carbon storage.

Another topic that requires further research is the relationship between the ideal age, subduction rates, and MOC. These quantities are often used interchangeably to describe the ventilation of oceans, with stronger MOC, increased subduction rates, and younger ages linked together. However, combination of the results presented here with the previous studies of changes in the MOC (Hogg et al. 2017) and subduction rates (Downes et al. 2017) shows that there are not simple one-to-one relationships between the quantities. In particular, while Downes et al. (2017) show that SAMW subduction is more sensitive to a shift in winds rather than an increase in winds, we have shown the opposite is true for volume of young waters and average of age in SAMW. This differing sensitivity occurs because the two quantities measure difference aspects of tracer transport: The ideal age is an integrated measure of the transport, depending on circulation and mixing over the pathways of water and over decades, whereas the subduction rate is a more local measure, both in terms of space and time scales. However, they are not independent quantities, and more research is need to understand the quantitative link between subduction and age, and how they relate to the uptake of heat and carbon.

Acknowledgments. D.W.W. and T.W.N.H. were supported by the National Science Foundation under NSF Proposal FESD-1338814, and P.S. was supported by an Australian Research Council Fellowship DE150100223. We thank Stephanie Downes for the MLD data and helpful discussions. Numerical simulations were conducted on the Australian National Computational Infrastructure (NCI), ANU, which is supported by the Commonwealth of Australia.

\section{REFERENCES}

Abernathey, R., and D. Ferreira, 2015: Southern Ocean isopycnal mixing and ventilation changes driven by winds. Geophys. Res. Lett., 42, 10357-10365, https://doi.org/10.1002/2015GL066238. 
Armour, K. C., J. Marshall, J. R. Scott, A. Donohoe, and E. R. Newsom, 2016: Southern Ocean warming delayed by circumpolar upwelling and equatorward transport. Nat. Geosci., 9, 549-554, https://doi.org/10.1038/ngeo2731.

Bindoff, N. L., and T. J. Mcdougall, 1994: Diagnosing climate change and ocean ventilation using hydrographic data. J. Phys. Oceanogr., 24, 1137-1152, https://doi.org/10.1175/15200485(1994)024<1137:DCCAOV > 2.0.CO;2.

Bracegirdle, T. J., E. Shuckburgh, J. B. Sallee, Z. Wang, A. J. Meijers, N. Bruneau, T. Phillips, and L. J. Wilcox, 2013: Assessment of surface winds over the Atlantic, Indian, and Pacific Ocean sectors of the Southern Ocean in CMIP5 models: Historical bias, forcing response, and state dependence. J. Geophys. Res. Atmos., 118, 547-562, https:// doi.org/10.1002/jgrd.50153.

Bryan, F. O., G., Danabasoglu, P. R. Gent, and K. Lindsay, 2006: Changes in ocean ventilation during the 21 st century in the CCSM3. Ocean Modell., 15, 141-156, https://doi.org/10.1016/ j.ocemod.2006.01.002.

Cai, W., 2006: Antarctic ozone depletion causes an intensification of the Southern Ocean super-gyre circulation. Geophys. Res. Lett., 33, L03712, https://doi.org/ 10.1029/2005GL024911.

, and T. Cowan, 2007: Trends in Southern Hemisphere circulation in IPCC AR4 models over 1950-99: Ozone depletion versus greenhouse forcing. J. Climate, 20, 681-693, https:// doi.org/10.1175/JCLI4028.1.

_, , S. Godfrey, and S. Wijffels, 2010: Simulations of processes associated with the fast warming rate of the southern midlatitude ocean. J. Climate, 23, 197-206, https://doi.org/ 10.1175/2009JCLI3081.1.

DeVries, T., and F. Primeau, 2011: Dynamically and observationally constrained estimates of water-mass distributions and ages in the global ocean. J. Phys. Oceanogr., 41, 2381-2401, https://doi.org/10.1175/JPO-D-10-05011.1.

D'Orgeville, M., M. H. England, K. J. Meissner, and W. P. Sijp, 2010: On the Southern Hemisphere westerlies control of glacial-interglacial atmospheric $\mathrm{CO}_{2}$ variations. Geophys. Res. Lett., 37, L21703, https://doi.org/10.1029/ 2010 GL045261.

Downes, S. M., C. Langlais, J. P. Brook, and P. Spence, 2017: Regional impacts of the westerly winds on Southern Ocean Mode and Intermediate Water subduction. J. Phys. Oceanogr., 47, 2521-2530, https://doi.org/10.1175/JPO-D-17-0106.1.

England, M. H., 1995: The age of water and ventilation timescales in a global ocean model. J. Phys. Oceanogr., 25, 2756-2777, https://doi.org/10.1175/1520-0485(1995)025<2756: TAOWAV $>2.0 . \mathrm{CO} ; 2$.

Farneti, R., and P. R. Gent, 2011: The effects of the eddy-induced advection coefficient in a coarse-resolution coupled climate model. Ocean Modell., 39, 135-145, https://doi.org/10.1016/ j.ocemod.2011.02.005.

Fine, R. A., S. Peacock, M. E. Maltrud, and F. O. Bryan, 2017: A new look at ocean ventilation time scales and their uncertainties. J. Geophys. Res. Oceans, 122, 3771-3798, https:// doi.org/10.1002/2016JC012529.

Gao, L., S. R. Rintoul, and W. Yu, 2018: Recent wind-driven change in Subantarctic Mode Water and its impact on ocean heat storage. Nat. Climate Change, 8, 58-63, https://doi.org/ 10.1038/s41558-017-0022-8.

Gille, S. T., 2008: Decadal-scale temperature trends in the Southern Hemisphere ocean. J. Climate, 21, 4749-4765, https:// doi.org/10.1175/2008JCLI2131.1.
Gnanadesikan, A., J. L. Russell, and F. Zeng, 2007: How does ocean ventilation change under global warming? Ocean Sci., $\mathbf{3}$, 43-53, https://doi.org/10.5194/os-3-43-2007.

Griffies, S. M., 2012: Elements of the Modular Ocean Model (2012 release with updates). GFDL Ocean Group Tech. Rep. 7, 618 pp.

Hall, T. M., and T. W. Haine, 2002: On ocean transport diagnostics: The idealized age tracer and the age spectrum. J. Phys. Oceanogr., 32, 1987-1991, https://doi.org/10.1175/1520-0485(2002) 032<1987:OOTDTI $>2.0$. CO;2.

Hogg, A. M., P. Spence, O. A. Saenko, and S. M. Downes, 2017: The energetics of Southern Ocean upwelling. J. Phys. Oceanogr., 47, 135-153, https://doi.org/10.1175/JPO-D16-0176.1.

Large, W., and S. G. Yeager, 2009: The global climatology of an interannually varying air-sea flux data set. Climate Dyn., 33, 341-364, https://doi.org/10.1007/s00382-0080441-3.

Le Quéré, C., and Coauthors, 2007: Saturation of the Southern Ocean $\mathrm{CO}_{2}$ sink due to recent climate change. Science, 316, 1735-1738, https://doi.org/10.1126/science.1136188.

Roemmich, D., J. Church, J. Gilson, D. Monselesan, P. Sutton, and S. Wijffels, 2015: Unabated planetary warming and its ocean structure since 2006. Nat. Climate Change, 5, 240-245, https:/ doi.org/10.1038/nclimate2513.

Russell, J. L., K. W. Dixon, A. Gnanadesikan, R. J. Stouffer, and J. R. Toggweiler, 2006: The Southern Hemisphere westerlies in a warming world: Propping open the door to the deep ocean. J. Climate, 19, 6382-6390, https://doi.org/10.1175/JCLI3984.1.

Sabine, C. L., and Coauthors, 2004: The oceanic sink for anthropogenic $\mathrm{CO}_{2}$. Science, 305, 367-371, https://doi.org/10.1126/ science.1097403.

Saenko, O. A., J. C. Fyfe, and M. H. England, 2005. On the response of the oceanic wind-driven circulation to atmospheric $\mathrm{CO}_{2}$ increase. Climate Dyn., 25, 415-426, https://doi.org/ 10.1007/s00382-005-0032-5.

Sarmiento, J. L., N. Gruber, M. A. Brzezinski, and J. P. Dunne, 2004: High-latitude controls of thermocline nutrients and low latitude biological productivity. Nature, 427, 56-60, https:// doi.org/10.1038/nature02127.

Sijp, W. P., and M. H. England, 2008: The effect of a northward shift in the southern hemisphere westerlies on the global ocean. Prog. Oceanogr., 79, 1-19, https://doi.org/10.1016/ j.pocean.2008.07.002.

Son, S. W., and Coauthors, 2008: The impact of stratospheric ozone recovery on the Southern Hemisphere westerly jet. Science, 320, 1486-1489, https://doi.org/10.1126/science.1155939.

Spence, P., S. M. Griffies, M. H. England, A. M. Hogg, O. A. Saenko, and N. C. Jourdain, 2014: Rapid subsurface warming and circulation changes of Antarctic coastal waters by poleward shifting winds. Geophys. Res. Lett., 41, 4601-4610, https://doi.org/10.1002/2014GL060613.

Stein, U., and P. Alpert, 1993: Factor separation in numerical simulations. J. Atmos. Sci., 50, 2107-2115, https://doi.org/ 10.1175/1520-0469(1993)050<2107:FSINS > 2.0.CO;2.

Swart, N. C., and J. C. Fyfe, 2012: Observed and simulated changes in the Southern Hemisphere surface westerly wind-stress. Geophys. Res. Lett., 39, L16711, https://doi.org/10.1029/ 2012GL052810.

Thomas, J. L., D. W. Waugh, and A. Gnanadesikan, 2015: Southern Hemisphere extratropical circulation: Recent trends and natural variability. Geophys. Res. Lett., 42, 5508-5515, https:// doi.org/10.1002/2015GL064521. 
Thompson, D. W., S. Solomon, P. J. Kushner, M. H. England, K. M. Grise, and D. J. Karoly, 2011. Signatures of the Antarctic ozone hole in Southern Hemisphere surface climate change. Nature Geosci., 4, 741-750, https://doi.org/10.1038/ ngeo1296.

Ting, Y. H., and M. Holzer, 2017: Decadal changes in Southern Ocean ventilation inferred from deconvolutions of repeat hydrographies. Geophys. Res. Lett., 44, 5655-5664, https:// doi.org/10.1002/2017GL073788.
Waugh, D. W., 2014: Changes in the ventilation of the southern oceans. Philos. Trans. Roy. Soc., 372A, 20130269, https:// doi.org/10.1098/rsta.2013.0269.

, F. Primeau, T. DeVries, and M. Holzer, 2013: Recent changes in the ventilation of the southern oceans. Science, 339, 568570, https://doi.org/10.1126/science.1225411.

Winton, M., 2000: A reformulated three-layer sea ice model. J. Atmos. Oceanic Technol., 17, 525-431, https://doi.org/ 10.1175/1520-0426(2000)017<0525:ARTLSI >2.0.CO;2. 